\title{
The Effect of Educational-supportive Interventions on Distress Tolerance of Parents of Premature Infants Hospitalized in the Neonatal Intensive Care Unit: A Quasi-experimental study
}

\section{Zahra Pourmovahed}

Shahid Sadoughi University of Medical Sciences

Razieh Mahmoodi ( $\sim$ razieh.mahmoodi1360@gmail.com)

Shahid Sadoughi University of Medical Sciences

Hassan Zarei Mahmoud Abadi

Yazd University

Mohammad Reza Mahmoudi

Fasa University

\section{Research Article}

Keywords: Premature infants, Distress, Tolerance, Parents, Education

Posted Date: May 20th, 2021

DOI: https://doi.org/10.21203/rs.3.rs-535993/v1

License: (c) (1) This work is licensed under a Creative Commons Attribution 4.0 International License.

Read Full License 


\section{Abstract}

Background: Parents of premature infants are more likely to be exposed to stressful situations than parents of term infants. This study aimed to explore the effect of educational-supportive interventions on the tolerance of parents of premature infants admitted to the neonatal intensive care unit (NICU).

Methods: In this quasi-experimental study, the participants included 50 parents of premature infants admitted to one of the NICUs in Shiraz, Iran from October 2019 to May 2020. Parents were randomly assigned to intervention and control groups. The training package and its content were done for the intervention group in five 45-minute sessions for two weeks and three times in a week. The data were collected using a demographic questionnaire and Distress Tolerance Scale and analyzed by SPSS 24 using paired t-test, independent t-test, and chi-square test. It was considered statistically significant $(P<0.05)$.

Results: The mean scores of the mothers' and fathers' distress tolerance in the pre-intervention stage were $36.0 \pm 6.1,33.9 \pm 7.4$ in the control group $(P<0.14)$ and $(38.4 \pm 5.8),(38.0 \pm 5.9)$ in the experimental group $(P<0.001)$, respectively. After the intervention, mean scores of the mothers' and fathers' distress tolerance in the control group were $(35.9 \pm 5.3),(36.5 \pm 6.3)$ and in the experimental group (54.7 \pm 5.3$)$, $(53.0 \pm 6.0)$, which compared to before intervention had a significant increase $(P<0.001)$.

Conclusion: Supportive-educational programs can increase distress tolerance in parents of premature infants, facilitate the relationship between them and lead to increasing the quality of infants' care.

\section{Introduction}

According to the definition of the World Health Organization, infants born at the age of 20-37 weeks from the first day of the last menstrual period are considered premature infant [1]. Preterm birth is a worldwide epidemic with a global incidence of 15 million/year, and nearly 1 in 10 babies is stillborn preterm [2]. The prevalence rates of preterm delivery in different cities of Iran were reported between 5.6$39.4 \%$ [3]. Many premature babies have many problems when they are born and need special care [4]. The stress from premature birth is intensified with prolonged hospitalization of the premature infant [5]. About $77 \%$ of mothers show clear signs of psychological trauma even up to one month later and $49 \%$ show the symptoms up to one year after the birth of a premature baby, affecting a person's quality of life if such symptoms become chronic. Approximately 28 to 70 percent of mothers of premature infants suffer from high level of stress [6]. Researches showed that mothers who are separated from their babies had high level of anxiety and depression and demonstrated numerous psychological reactions [7-9]. Maladaptive responses to stress reduce the level of distress tolerance in mother [10]. Interventional program focusing on relieving mothers' anxiety and stress is needed to prevent maternal stress and anxiety at an early stage [11]. Families with premature infants need education and supportive interventions to increase the level of distress tolerance and improve parents' well-being .Fathers also need emotional support. Education will have positive effects on a higher level of parental adjustment. Supporting of the family 
and giving information to them are necessary to control of their situation, gain a more realistic view about their baby, and participate in their baby care $[9,12,13]$.

Considering that there are few studies in Iran on supporting parents with premature infants to cope with distress and there is an urgent need to strengthen the family in families with premature infants, it is necessary to develop a supportive-educational program. In this regard, nurses have a unique opportunity to help parents. Other studies were done on one of parents especially on mothers but this study was done on both parents to facilitate the relationship between them and increasing the quality of infant,s care.

This study aimed to determine the effect of educational-supportive interventions on the distress tolerance of parents of premature infants admitted to NICU.

\section{Method}

This quasi-experimental study was done from October 2019 to May 2020.The sample included parents of premature infants hospitalized in one of the NICUs of the Hazrat Zeinab Hospital (due to having five sections of NICU) in Shiraz, Iran. The sample size was calculated for each group as 25 mothers and 25 fathers) at $95 \%$ confidence level and statistical power of $90 \%$ using the following equation [14]. $S_{1}$ and $S_{2}$ were unknown and were estimated from a pilot study with size of 5 . In each group, 24 parents were estimated, and in terms of $5 \%$ probability of falling sample, 25 parents were selected in each group.

$$
\begin{array}{rll}
d=2.5 & s 1=2.3 & a=0.05 \\
& s 2=2.8 & \beta=0.02
\end{array}
$$

$$
n=\frac{\left(Z_{1-\frac{\alpha}{2}}+Z_{1-\beta}\right)^{2}\left(S_{1}^{2}+S_{2}^{2}\right)}{d^{2}}
$$

$$
=\frac{(1.96+1.4)^{2}\left((2.3)^{2}+(2.8)^{2}\right)}{(2.5)^{2}} \cong 24
$$

In this way, the researcher referred to the NICU daily and if the parents were eligible, they were included in our study. Parents were randomly assigned to intervention and control groups. The cards with the words $\mathrm{C}$ and $\mathrm{M}$ written on them were prepared and each participant was asked to choose a card at random. Then parents with a card with the letter $\mathrm{C}$ in the control group and parents with a card with the letter $\mathrm{M}$ were located in the intervention group.

The inclusion criteria were the willingness to participate in the study, ability to care for the baby, having literacy, having Iranian nationality, being fluent in Persian, availability of both parents, fetal age of the baby being 30-36 weeks because infant mortality is significantly higher in infants born before 30 weeks of gestation, the baby's hospitalization for at least 14 days in the ward, the parents' non-attendance in educational-supportive courses related to the premature infant, and the parents' non-use of psychiatric 
drugs. The exclusion criteria were the infant's death, the parents' death, and having an infant with another disorder that could be diagnosed and cause maternal anxiety and frustration. Besides, the participants who were absent at two sessions of the training course and those who had a history of premature birth or hospitalization in the NICU were excluded from the study.

The instruments were a demographic questionnaire and Distress Tolerance Scale (DTS). It was built by Simons and Gaher in 2005 and have 15 items and four subscales called tolerance ( 3 items), absorption (3 items), regulation (3 items) and appraisal (6 items). Items were rated on a 5-point scale: (5) Strongly disagree, (4) Mildly disagree (3) Agree and disagree equally, (2) Mildly agree, (1) Strongly agree. High scores represent high distress tolerance. The minimum score is 15 and the maximum is 75 . Test-retest reliability was good (intra-class $r=.61$ ) [15]. The reliability of the scale was assessed by Azizi and coworkers (2010). They reported that Cronbach's alpha and the test-retest reliability of the scale were 0.67 and 0.79 , respectively [16].

After the admission of the premature infant the questionnaires were given to the parents. To prevent parental stress, each parent separately completed the questionnaires (mothers in the restroom next to the ward and fathers in the conference room). The control group did not receive any intervention except for routine ward care, breastfeeding training and kangaroo care. The intervention was conducted in two educational and supportive stages. In the educational stage, five 45-minute training sessions in 3 times a week were held face to face, both individually and in the groups. The same training sessions were held through WhatsApp groups due to lack of full presence and availability to parents. The training sessions included an introductory session, a baby care session, two sessions on stress reduction and tolerance, and question and answer session by the researcher and a psychologist using PowerPoint, Voice messages, and WhatsApp groups. At the end of the sessions, the parents were given an educational booklet. Besides, one day after the training stage, the support stage was implemented in the presence of the parents. To exchange their ideas and share information, the parents attended a room next to the ward for three days in five groups at the appointed time upon prior arrangements made with the manager and the head of the ward and talked for half an hour. Then, they spent half an hour together by the baby's bed, watching and caring for the baby. One month after the end of the supportive stage in the clinic, when the parents came to visit the pediatrician, the distress tolerance scale was completed again by the participants in both groups. The questionnaire was distributed by the researcher.

Our education was based on a comprehensive approach in the domain of family education that evaluates seven domains including communication, problem solving, emotional responses, roles, emotional involvement, general function, and behavioral control. This can be used to help couples who have some problems and families with a physically disabled member $[17,18]$.

To comply with ethical principles, the participants in the control group were given an educational package. Finally, the collected data were encoded and analyzed by SPSS 24 using paired t-test, independent t-test, and chi-square test at the significance level of 0.05 . 
The research proposal was approved by the Ethics Committee of Yazd Shahid Sadoughi University of Medical Sciences (IR.SSU.REC.1398.207). The research goals, anonymity of the information provided and voluntary participation were first explained and the participants then read and signed the written informed consent form; then, they completed the questionnaires.

\section{Results}

The mean age of mothers in the control and intervention groups was $27.0 \pm 4.0$ and $28.7 \pm 3.9$, respectively, and the mean age of fathers was $26.8 \pm 4.2$ and $29.01 \pm 4.1$ years, respectively. The mean weight of neonatal in the intervention group was $1887.0 \pm 434$ and in the control group was $1990.0 \pm 419$ $(P=0.39)$. The mean age of neonates in the intervention group was $33.8 \pm 1.78$ and in the control group was $32.1 \pm 1.8$ ( $P=0.17$ (.The two groups were compared in terms of demographic variables of age, level of education, occupation, etc. before the intervention and there was no significant difference (Table 1).

Table 1

Demographic characteristics of parents in two study groups

\begin{tabular}{|c|c|c|c|c|c|}
\hline \multirow{3}{*}{ Variable } & & & Intervention & Control & \multirow{3}{*}{ *P-Value } \\
\hline & & & $(n=25)$ & $(n=25)$ & \\
\hline & & & $\mathrm{N}(\%)$ & $\mathrm{N}(\%)$ & \\
\hline \multirow[t]{4}{*}{ Occupation } & Mother & Employee & $5(20)$ & $1(4)$ & \multirow[t]{2}{*}{0.08} \\
\hline & & Housewife & $20(80)$ & $24(96)$ & \\
\hline & \multirow[t]{2}{*}{ Father } & Employee & $23(92)$ & $21(84)$ & \multirow[t]{2}{*}{$<0.001$} \\
\hline & & Other & $2(8)$ & $4(16)$ & \\
\hline \multirow[t]{4}{*}{ Education } & \multirow[t]{2}{*}{ Mother } & Diploma & $11(44)$ & $12(48)$ & \multirow[t]{2}{*}{0.11} \\
\hline & & University & $14(56)$ & $13(52)$ & \\
\hline & \multirow[t]{2}{*}{ Father } & Diploma & $12(48)$ & $12(48)$ & \multirow[t]{2}{*}{0.16} \\
\hline & & University & $13(52)$ & $13(52)$ & \\
\hline \multirow{2}{*}{$\begin{array}{l}\text { Neonatal } \\
\text { Gender }\end{array}$} & Girl & & $13(52)$ & $14(56)$ & \multirow[t]{2}{*}{0.16} \\
\hline & Boy & & $12(48)$ & $11(44)$ & \\
\hline
\end{tabular}

* Chi-square test

The results of the independent samples t-test indicated that there was no statistically significant difference between the experimental and control groups before the intervention in terms of parental distress tolerance $(P>0.05)$. However, after the intervention, Mean score of distress tolerance was significantly higher among the intervention group than the control group $(P<0.001)$. Besides, the parental 
distress tolerance score in the experimental group showed a significant increase after the intervention ( $P$ $<0.001)$.The mean scores of the mothers' and fathers' distress tolerance in the pre-intervention stage were( $36.0 \pm 6.1),(33.9 \pm 7.4)$ in the control group and( $38.4 \pm 5.8),(38 \pm 5.9)$ in the experimental group, respectively. After the intervention, mean scores of the mothers' and fathers' distress tolerance in the control group were( $35.9 \pm 5.3)$, (36.5 \pm 6.3$)$ and in the experimental group (54.7 \pm 5.3$)$, (53.0 \pm 6.0$)$, which compared to before intervention had a significant increase $(P<0.001)$. (Table 2$)$.

Table 2

Comparison of the mean scores of parental distress tolerance in the control and Intervention groups before and after the intervention

\begin{tabular}{|c|c|c|c|c|}
\hline \multirow{2}{*}{\multicolumn{2}{|c|}{$\begin{array}{l}\text { Distress tolerance } \\
\text { Group }\end{array}$}} & \multirow{2}{*}{$\begin{array}{l}\text { Before } \\
\text { Intervention }\end{array}$} & \multirow{2}{*}{$\begin{array}{l}\text { After } \\
\text { Intervention } \\
\text { Mean } \pm \text { SD }\end{array}$} & \multirow[t]{2}{*}{ P-value* } \\
\hline & & & & \\
\hline \multirow[t]{3}{*}{ Mothers } & Control & $36.1 \pm 6.1$ & $35.9 \pm 5.3$ & 0.94 \\
\hline & Intervention & $38.4 \pm 5.8$ & $54.7 \pm 5.3$ & $<0.001$ \\
\hline & P-Value** & 0.15 & $<0.001$ & \\
\hline \multirow[t]{3}{*}{ Fathers } & Control & $33.9 \pm 7.4$ & $36.5 \pm 6.3$ & 0.14 \\
\hline & Intervention & $38.0 \pm 5.9$ & $53.0 \pm 6.0$ & $<0.001$ \\
\hline & P-Value** & 0.24 & $<0.001$ & \\
\hline
\end{tabular}

* Paired t test

** Independent $t$ test

The mean scores on all subscales of parental distress tolerance before and after the intervention were not significantly different for the control group (Table 3). 
Table 3

Comparison of the mean score of parental distress tolerance subscales before and after intervention in control and Intervention groups

\begin{tabular}{|c|c|c|c|c|c|c|}
\hline \multirow{2}{*}{\multicolumn{2}{|c|}{$\begin{array}{l}\text { Subscales } \\
\text { Group }\end{array}$}} & \multirow[t]{2}{*}{ Time } & \multirow{2}{*}{$\begin{array}{l}\text { Tolerance } \\
\text { Mean } \pm \text { SD }\end{array}$} & \multirow{2}{*}{$\begin{array}{l}\text { Absorption } \\
\text { Mean } \pm \text { SD }\end{array}$} & \multirow{2}{*}{$\begin{array}{l}\text { Appraisal } \\
\text { Mean } \pm \text { SD }\end{array}$} & \multirow{2}{*}{$\begin{array}{l}\text { Regulation } \\
\text { Mean } \pm \text { SD }\end{array}$} \\
\hline & & & & & & \\
\hline \multirow[t]{6}{*}{ Mothers } & \multirow[t]{3}{*}{ Control } & Before & $7.4 \pm 1.3$ & $7.1 \pm 1.3$ & $14.2 \pm 2.6$ & $7.4 \pm 1.3$ \\
\hline & & After & $7.2 \pm 1.2$ & $7.2 \pm 1.2$ & $14.5 \pm 1.9$ & $7.2 \pm 1.2$ \\
\hline & & P-value* & 0.69 & 0.83 & 0.66 & 0.69 \\
\hline & \multirow[t]{3}{*}{ Intervention } & Before & $7.8 \pm 1.2$ & $7.6 \pm 1.4$ & $15.3 \pm 2.2$ & $7.8 \pm 1.2$ \\
\hline & & After & $11.0 \pm 1.3$ & $11.0 \pm 1.1$ & $21.8 \pm 2.5$ & $11.0 \pm 1.3$ \\
\hline & & P-value* & $<0.001$ & $<0.001$ & $<0.001$ & $<0.001$ \\
\hline \multirow[t]{6}{*}{ Fathers } & \multirow[t]{3}{*}{ Control } & Before & $6.7 \pm 1.6$ & $6.9 \pm 1.6$ & $13.6 \pm 3.2$ & $6.7 \pm 1.6$ \\
\hline & & After & $7.1 \pm 1.2$ & $7.4 \pm 1.4$ & $14.5 \pm 2.9$ & $7.1 \pm 1.2$ \\
\hline & & P-value* & 0.27 & 0.14 & 0.21 & 0.27 \\
\hline & \multirow[t]{3}{*}{ Intervention } & Before & $7.6 \pm 1.3$ & $7.6 \pm 1.2$ & $15.3 \pm 2.5$ & $7.6 \pm 1.3$ \\
\hline & & After & $10.6 \pm 1.5$ & $10.7 \pm 1.4$ & $21.0 \pm 2.3$ & $10.6 \pm 1.5$ \\
\hline & & P-value* & $<0.001$ & $<0.001$ & $<0.001$ & $<0.001$ \\
\hline
\end{tabular}

* Paired t test

\section{Discussin}

This study showed that supportive-educational programs can increase distress tolerance of parents with premature neonates. Reyhani et al. stated that self-care education reduces psychological stress and increases the tolerance of mothers with premature infants in the NICU [19]. which is consistent with the results of the present study. After educational intervention in both studies, a significant increase was observed in each of the dimensions of anxiety tolerance. The difference between these two studies was in the type of educational intervention which in the present study was supportive and one month after the intervention all dimensions of anxiety tolerance became significant, but in the Reyhani study except for the adjustment dimension, none of the subsets of anxiety tolerance scale in the follow-up phase do not hang yourself.

In the study of Lotfi Kashani et al. child care education reduced maternal anxiety, the results of which were consistent with the present study. Both studies showed that support and care have a positive effect on reducing mothers' stress, which has increased their hope and value in life, as well as gives them a sense of balance in life and teaches mothers how to cope with their child's illness [20]. In fact, giving education creates a feeling of control and power on the part of the parents over their situation and causes 
them to participate more in caring for the baby. Also find a realistic view of the baby. In a study by Karami et al., the results showed that the implementation of educational-supportive intervention program significantly reduced the stress of preterm infants, but was not effective during hospitalization due to the short duration of the study [14]. Which is consistent with the present study, but the difference between the two studies was that the present study did not examine the length of hospital stay.

The contents of the information-emotional support program can reduce stress levels in fathers of premature infants admitted to NICU [21]. In this regard, Proet et al. stated that by recognizing the amount and type of psychological stress in fathers, nurses can have more support for fathers in their new role, and young fathers and those with very premature infants may need support and additional resources [22].

Supportive intervention according to individual needs reduce anxiety and stress of parents [23]. Also, in the study of Pace et al. most parents called for supportive interventions [24]. It seems that without intervention for parents, psychological stress is not reduced enough. In this regard, the study of Carvalho et al. also showed that psychological support for mothers with premature infants, by meeting the needs of the mother in relation to the condition of her baby and informing about prematurity, reduces maternal stress and tension [25].

Mothers of infants admitted to the NICU are emotionally vulnerable. Identifying and treating their emotional disorders in the form of depression and anxiety is a comprehensive part of nursing care that increases mothers' ability to interact with the nursing team and ultimately with the baby [26]. Therefore in order to cope with problems, interventions should be done for them [27].

In this regard, more research and interventions should be done that help reduce parental stress and the goal is to improve the emotional health of parents [28]. All the studies support the results of the present study, despite the fact that different intervention tools and methods have been used. Explaining the effectiveness of educational-supportive program on increasing the tolerance of distress of parents participating in this study, it can be said that educational interventions make parents better aware of how to care for their baby and recognize their strengths and weaknesses and to correct and try to strengthen them. Creating awareness of abilities helps parents to deal with problems in a more efficient and appropriate way, increase their distress tolerance. Strengths of this study were building confidence, security, emotional stability, learning readiness and social development of parents. One limitation of this study was application of the available sampling method. Also, if this study was done in longer time, the results were more generalizable.

\section{Conclusion}

Supportive-educational programs can increase distress tolerance of parents of premature infants, facilitate the relationship between them and lead to increasing the quality of infants' care. Therefore, it is suggested that healthcare workers arrange such educational and supportive program for parents in NICU. 


\section{Abbreviations}

NICU: neonatal intensive care unit.

\section{Declarations}

\section{Ethical approval and consent to participate}

This study was approved by the ethics committee of Yazd Shahid Sadoughi University of Medical Sciences (IR.SSU.REC.1398.207). The informed written consent was obtained from all participants. All methods were carried out in accordance with relevant guidelines and regulations.

\section{Consent for publication}

Not applicable.

\section{Availability of data and materials}

The datasets and analyzed in this study can be made available by the corresponding author at reasonable request.

\section{Competing interests}

None of the authors have any competing interests.

\section{Funding}

The present study was financially supported by the Vice Chancellor of Research of Yazd Sadoughi University of Medical Sciences, Yazd, Iran. The funding body did not play any roles in the in the design of the study; collection, analysis, and interpretation of data; and in writing the manuscript.

\section{Authors' contributions}

RM, ZP, and HZM contributed to the design and MRM to the statistical analysis. RM and ZP participated in most of the study steps. RM, ZP, and HZM prepared the manuscript. All authors have read and approved the content of the manuscript.

\section{ACKNOWLEDGMENT}

This article is derived from a thesis affiliated to the Yazd Sadoughi University of Medical Sciences, with the research project (code 6798). The authors thank all parents who participated in the study.

\section{References}


1. Thanh NX, Toye J, Savu A, Kumar M, Kaul P. Health service use and costs associated with low birth weight: a population level analysis. J Pediatr. 2015; 167:551-6. e1-3. [PubMed] [Google Scholar].

2. Purisch SE, Gyamfi-Bannerman C. Epidemiology of preterm birth. Semin Perinatol. 2017; 41:387-91. [PubMed] [Google Scholar].

3. Dolatian M, Mirabzadeh A, Forouzan AS, Sajjadi H, Majd HA, Moafi F. Preterm delivery and psychosocial determinants of health based on World Health Organization model in Iran: a narrative review. Global J Health Sci 2013;5(1):52.

4. Lawn JE, Kinney MV, Belizan JM, Mason EM, McDougall L, Larson J, et al. Born too soon: accelerating actions for prevention and care of 15 million newborns born too soon. Reprod Health. 2013;10 (Suppl 1):6-10

5. Arnold L, Sawyer A, Rabe H, Abbott J, Gyte G, Duley L, et al. Parents' first moments with their very preterm babies: a qualitative study. BMJ open. 2013; 3(4).

6. Gray PH, Edwards DM, O'Callaghan MJ, Cuskelly M, Gibbons K. Parenting stress in mothers of very preterm infants -influence of development, temperament and maternal depression. Early Hum Dev. 2013; 89(9):625-9.

7. Hosseini SM, Masoudi R, Mamori GA. [The effect of relaxation training on breastfeeding self-efficacy of mothers with preterm infants: A randomized clinical trial]. Journal of Clinical Nursing and Midwifery. 2014; 3(2):37-45. (Persian).

8. Ong SL, Abdullah KL, Danaee M, Soh KL, Soh KG, Japar S.Stress and anxiety among mothers of premature infants in a Malaysian neonatal intensive care unit. J Reprod Infant Psychol. 2019; 37:193-205.

9. Kawafha MM. Parental stress in the neonate intensive care unit and its association with parental and infant characteristics.J Neonatal Nurs. 2018; 24:266-72.

10. Valizadeh L, Hosseini MB, Heydarpoor Damanabad Z, Rahkar Farshi M, Asgari Jafarabadi M, Ranjbar Kochaksaraie F. Effect of NICU department orientation program on mother's anxiety: A randomized clinical trial. J Caring Sci. 2016; 5:205-14.

11. Rutherford HJ, Goldberg B, Luyten P, Bridgett DJ, Mayes LC. Parental reflective functioning is associated with tolerance of infant distress but not general distress: Evidence for a specific relationship using a simulated baby paradigm. Infant Behavior and Development. 2013;36(4):635-41

12. Mansourian M, Ziapour $A$, Kazemian $M$, et al. Assessment of educational performance of nurses in neonatal intensive care unit from parents' perspective. J Educ Health Promot. 2020; 9:8.

13. Askari M, Noah SBM, Hassan SAB, Baba MB. Comparison the effects of communication and conflict resolution skills training on marital satisfaction. International Journal of Psychological Studies. 2012; 4(1):182.

14. Karami K, Rostami S, Ghadirian F. Effect of educational- supportive interventions on premature infants' lentgh of hospitalization and maternal stress. Yafte. 2009; 11 (2):67-73.

15. Simons JS, Gaher RM. The Distress Tolerance Scale: Development and Validation of a Self-Report Measure. Motivation and Emotion. 2005; 29(2):83-102. 
16. Azizi Alireza; Mirzaei Azadeh; Shams Jamal . Correlation between distress tolerance and emotional regulation with students smoking dependence.. Hakim Research Journal. 2010; 13(1):11-18.

17. Pourmovahed Z, Zareei Mahmoodabadi H, Yassini Ardekani SM, Fallahzadeh $H$,Tavangar $H$, Mazloomy Mahmoodabad SS. Validation of the Family Stability Questionnaire in married couples: a confirmatory factor analysis. Electronic Physician 2018; 10(8): 7185-7195.

18. Mahmoodabadi HZ, Bahrami F, Ahmadi A, Etemadi O, Zadeh MSF. The effectiveness of retraining attribution styles (cognitive therapy) on dimensions of family functioning in divorce applicant couples. International Journal of Psychological Studies. 2012;4(2):257-63.

19. Reyhani T, Sekhavat Pour Z, Heidarzadeh M, Mousavi SM, Mazloom SR. Investigating the effects of spiritual self-care training on psychological stress of mothers with preterm infants admitted in NICU. The Iranian Journal of Obstetrics, Gynecology and Infertility. 2014; 17(97):18-27.

20. Lotfi Kashani F, Vaziri SH, Arjmand S, Misavi SM, Hashemiyeh M. Effectiveness of spiritual interventions to reduce maternal distress in children with cancer. Article in Persian. J Med Ethics. 2012; 20 (6):554-564.

21. Shahkolahi Z, Abdeyazdan Z, Mehrabi T, Hajiheidari M. Supporting fathers of premature infants hospitalized in Neonatal Intensive Care Unit (NICU). Journal of Critical Care Nursing. 2014; 7(1):3140.

22. Prouhet PM, Gregory MR, Russell CL, Yaeger LH. Fathers' Stress in the Neonatal Intensive Care Unit: A Systematic Review.Adv Neonatal Care. 2018; 18(2):105-120.

23. Cano Giménez E, Sánchez-Luna M. Providing parents with individualized support in a neonatal intensive care unit reduced stress, anxiety and depression. ActaPaediatr 2015; 104:300-305. doi:10.1111/apa.12984.

24. Pace CC, Spittle A J, Molesworth CM, Lee K J et al. Evolution of depression and anxiety symptoms in parents of very preterm infants during the newborn Period. JAMA Pediatr 2016;170(9):863-870.

25. Vita Carvalho AE, Martins Linhares MB, PereiraPadovani FH, Martinez FE. Anxiety and Depression in mothers of preterm infants and psychological intervention during hospitalization in neonatal ICU. The Spanish Journal of Psychology2009; 12(1):161-170.

26. Segre LS, Chuffo-Siewert R, Brock RL, O’Hara MW. Emotional distress in mothers of preterm hospitalized infants:a feasibility trial of nurse-deliveredtreatment. Journal of Perinatology. 2013;1-5.

27. Ghorbani M, Dolatian M, Shams J, Alavi-Majd H. Anxiety, post-traumatic stress disorder and social supports among parents of premature and full-term infants. Iran Red Crescent Med J. 2014; 6(3):6573

28. Wormald F, Tapi JL,Torres G, Cánepa P, Aurelia González M, Rodríguez D, et al. Stress in parents of very low birth weight preterm infants hospitalized in neonatalintensive care units. A multicenter study. Arch Argent Pediatr 2015; 113 (4): 303-9. 